\title{
PROPOSTA E MAPEAMENTO DE CORREDORES ECOLÓGICOS NA REGIÃO dO VALE DO PARAÍbA PAULISTA A PARTIR DE TÉCNICAS DE GEOPROCESSAMENTO PARA CONSERVAÇÃO DE ABELHAS NATIVAS DO BRASIL.
}

DOI 10.37619/issn2447-5378.v7i1.296.104-115

\author{
T. M. M. Fernandes*; E. L. Pagotto \\ Faculdade de Tecnologia de Jacareí - Professor Prof. Francisco de Moura \\ R. Faria Lima, 155 - Jardim Santa Maria, Jacareí - SP, CEP.: 12328-070, Brasil. \\ "thalesfernandes866@gmail.com
}

\begin{abstract}
RESUMO: As abelhas são importantes polinizadores, auxiliando na conservação dos ecossistemas e no aumento da produtividade agrícola. Este artigo traz uma proposta de corredores ecológicos para conservação de abelhas nativas na região do Vale do Paraíba como estratégia para aliar conservação da biodiversidade, proteção dos recursos naturais e geração de emprego e renda. Técnicas de geoprocessamento auxiliaram na identificação de locais adequados para alocação dos corredores ecológicos, produzindo e integrando dados e informações para tomada de decisão de agentes locais. Os procedimentos adotados foram a elaboração de uma base georreferenciada a partir de dados obtidos junto a órgãos públicos nacionais e estaduais, posteriormente analisados e integrados. Como resultados, o estudo apresenta as áreas mais favoráveis à criação dos corredores ecológicos, indicando em cada município aquelas que podem ser priorizadas para a meliponicultura e conservação ambiental.
\end{abstract}

PALAVRAS-CHAVE Abelhas nativas. Corredores ecológicos. Meliponários. Recursos naturais. Geoprocessamento. Mapeamentos.

\begin{abstract}
Bees are important pollinators, helping to conserve ecosystems and to increase agricultural productivity. This article presents a proposal for ecological corridors for the conservation of native bees in the Vale do Paraíba region as a strategy to combine biodiversity conservation, protection of natural resources and generation of jobs and income. Geoprocessing techniques helped to identify suitable locations for the allocation of ecological corridors, producing and integrating data and information for decision-making by local agents. The adopted procedures were the elaboration of a georeferenced base from data obtained from national and state public agencies, which were analyzed and integrated. As a result, the study presents the most favorable areas for the creation of ecological corridors, indicating in each municipality those that can be prioritized for meliponiculture and environmental conservation.
\end{abstract}

KEYWORDS: Native bees. Ecological corridors. Meliponarios. Natural resources. Geoprocessing. Mappings.

\section{INTRODUÇÃO}

Geoprocessamento é um conjunto de tecnologias capaz de fazer coletas e tratamento de dados espaciais, integrando diversas áreas de conhecimentos, como: cartografia, sensoriamento remoto, banco de dados, estatística, análises ambientais e territoriais, cadastros, processamento de dados etc. (INPE, 2012). 


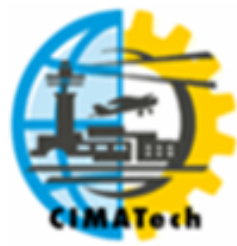

\section{Congress of Industrial \\ Management and Aeronautical \\ Technology}

ISSN $2447-5378$

Os dados são processados por sistemas de informação geográfica (SIG). O SIG é eficiente para o georreferenciamento dos dados coletados, oferecendo as análises espaciais e manipulação das informações. O formato das informações disponíveis em um SIG pode ser em camadas vetoriais, raster e tabulares. Essas informações também podem ser disponibilizadas em ambiente web para acesso em grande massa, consultas, obtenção de dados, gerenciamento etc. (INPE, 2012).

Para Burrough (1986), os sistemas de informações geográficas são um conjunto poderoso de ferramentas para coletar, armazenar, recuperar, transformar e visualizar dados sobre o mundo real. Para Cowen (1988), constituem um sistema de suporte à decisão que integra dados referenciados espacialmente num ambiente de respostas a problemas. Segundo Sena, Neto e Leite (2012) o SIG é importante para o monitoramento e apoio da biodiversidade, devido a capacidade coleta de dados para diversas análises.

O geoprocessamento aplicado a análise ambiental permite identificar variedades de biomas no espaço, seja ele por meio de mapeamentos já realizados, onde pode-se obter a base de dados, na maioria, por órgãos públicos ou elaborado por interpretação de imagens atuais de satélites, levantamentos de campo, envolvendo a análise espacial (INPE, 2012). Para Medeiros e Câmara (2001) a área de diagnóstico ambiental objetiva estabelecer estudos específicos sobre regiões de interesse, com vistas a projetos de ocupação ou preservação.

No âmbito das abelhas nativas, a meliponicultura se enquadra perfeitamente dentro dos conceitos de diversificação e utilização sustentável dos recursos naturais, pois é uma atividade que pode ser integrada ao manejo florestal, plantio de fruteiras e/ou culturas de ciclos curtos, em muitos casos, pode contribuir no aumento de produção agrícola (ALVES et al., 2011).

Venturieri (2006) afirma que a meliponicultura, ou criação de abelhas indígenas sem ferrão, tem se mostrado como uma excelente alternativa para a geração de renda entre as populações interioranas, podendo enquadrar-se perfeitamente nos preceitos de uso sustentável dos recursos naturais, sem a necessidade da remoção da cobertura vegetal nativa.

É uma atividade que necessita de pouco investimento inicial e pode ser desenvolvida em pequenas propriedades rurais, além de permitir que o agricultor familiar mantenha suas outras atividades culturalmente, tendo na nova atividade um complemento de sua renda familiar (CAMARGO, 2004).

Segundo Dutra (2008), os meliponíneos, abelhas nativas, sociais e sem ferrão, ocupam grande parte das regiões de clima tropical no planeta, especialmente na América do Sul. No Brasil, são conhecidas mais de 400 espécies de abelhas nativas, as quais são responsáveis em $90 \%$ pela polinização de vegetais nativos. Atualmente são criadas comercialmente em agrupamentos de colônias, denominados meliponários, que constituem a meliponicultura.

O presente artigo apresenta uma proposta para contribuir com a conservação de abelhas nativas do Brasil, na região do Vale do Paraíba, localizada no interior do Estado de São Paulo. Utilizando técnicas do geoprocessamento, para isso, foram definidos objetivos específicos, como: coletar dados de campo com informações sobre colmeias e iscas para capturas e reprodução de abelhas, produzir base de dados geográficas com informações de apoio ao manejo das abelhas, por meio de análise geoespacial recomendar áreas para implantação de corredores ecológicos e novas colônias.

A implementação de corredores ecológicos que conectam fragmentos de habitat configura-se como uma estratégia de conservação da biodiversidade que permite a proteção dos recursos naturais, favorecendo o fluxo de animais e de sementes entre os fragmentos anteriormente isolados. Técnicas de geoprocessamento e análise espacial podem auxiliar na determinação dos locais mais adequados para alocação dos corredores ecológicos, uma vez que permitem a obtenção, organização e disponibilização dos dados de forma eficiente e integradora (MORETTI, 2011). 


\section{MATERIAIS E MÉTODOS}

Para sua execução, o projeto foi subdividido em três etapas, como mostra a Figura 1.
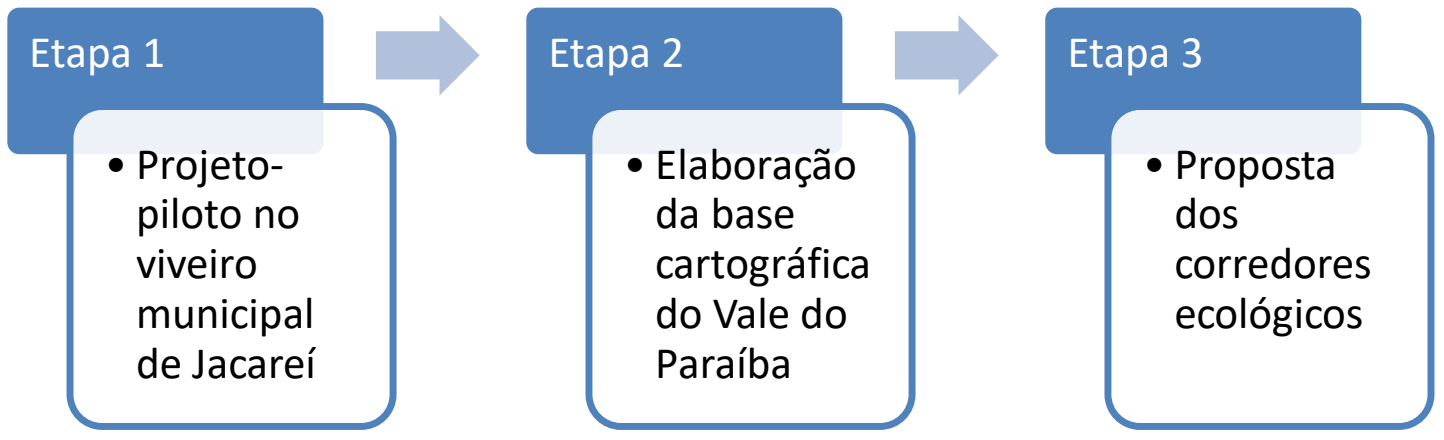

Figura 1. Etapas do projeto.

Na Etapa 1 foi definida como área de estudo do projeto-piloto o Viveiro Municipal Seo Moura, no Município de Jacareí - SP, ocupado por uma área de cerca de 15 ha. Foram confeccionadas 80 iscas feitas de garrafas pets e atrativo à base de feromônio, as quais foram instaladas no Viveiro para captura das abelhas no período de 2019 - 2020. Os trabalhos de campo de manejo das iscas e dos animais foram conduzidos por uma equipe técnica específica seguindo os procedimentos do "Guia Ilustrado para Criação e Manejo de Meliponídeos” (GUIMARÃES, PAGOTTO, 2020). O local escolhido para instalação das iscas foi definido pela equipe de campo, considerando os seguintes critérios: elas deveriam ser instaladas longe de interferências (trilhas, clareiras, etc.), em locais acessíveis para manutenção semanal (limpeza, colocação de feromônio) e cobrindo a maior área possível em meio à vegetação arbórea do Viveiro.

As coletas de coordenadas foram feitas pelo aplicativo Latitude Longitude Location, disponível no Play Store para smartfones Android, coletadas por uma equipe de campo. Cada coordenada representa um identificador de isca, que foi colocada em uma tabela Excel, e realizado um controle de qualidade dos dados coletados, verificando os possíveis erros e realizando ajustes necessários. Em seguida foi criado um arquivo em formato CSV (Valores Separados por Vírgula), que é um tipo especial de arquivo que possibilita o georreferenciamento dos dados em SIG, e em seguida o arquivo foi transformado de CSV para shapefile, que é um formato popular de arquivo contendo dados geoespaciais em forma de vetor utilizado em SIG. Como as coordenadas coletadas estavam com valores decimais, a projeção escolhida foi a WGS-84 (Sistema Geodésico Mundial). O sistema de referência da rede de satélites GPS (Global Positioning System) é o sistema WGS-84, ou Word Geodetic System 1984 (VERONEZ, 1998).

O software utilizado para o georreferenciamento das coordenadas coletadas foi o QGIS Desktop 3.4.15. O QGIS é um SIG de código aberto licenciado segundo a licença pública geral que suporta inúmeros formatos de vetores, rasters, bases de dados e funcionalidades que permite-se visualizar, gerir, editar, analisar dados, e criar mapas para impressão (QGIS, 2020). Ao final desta etapa foi possível obter um mapa da área-piloto do projeto, apresentada na Figura 2. 


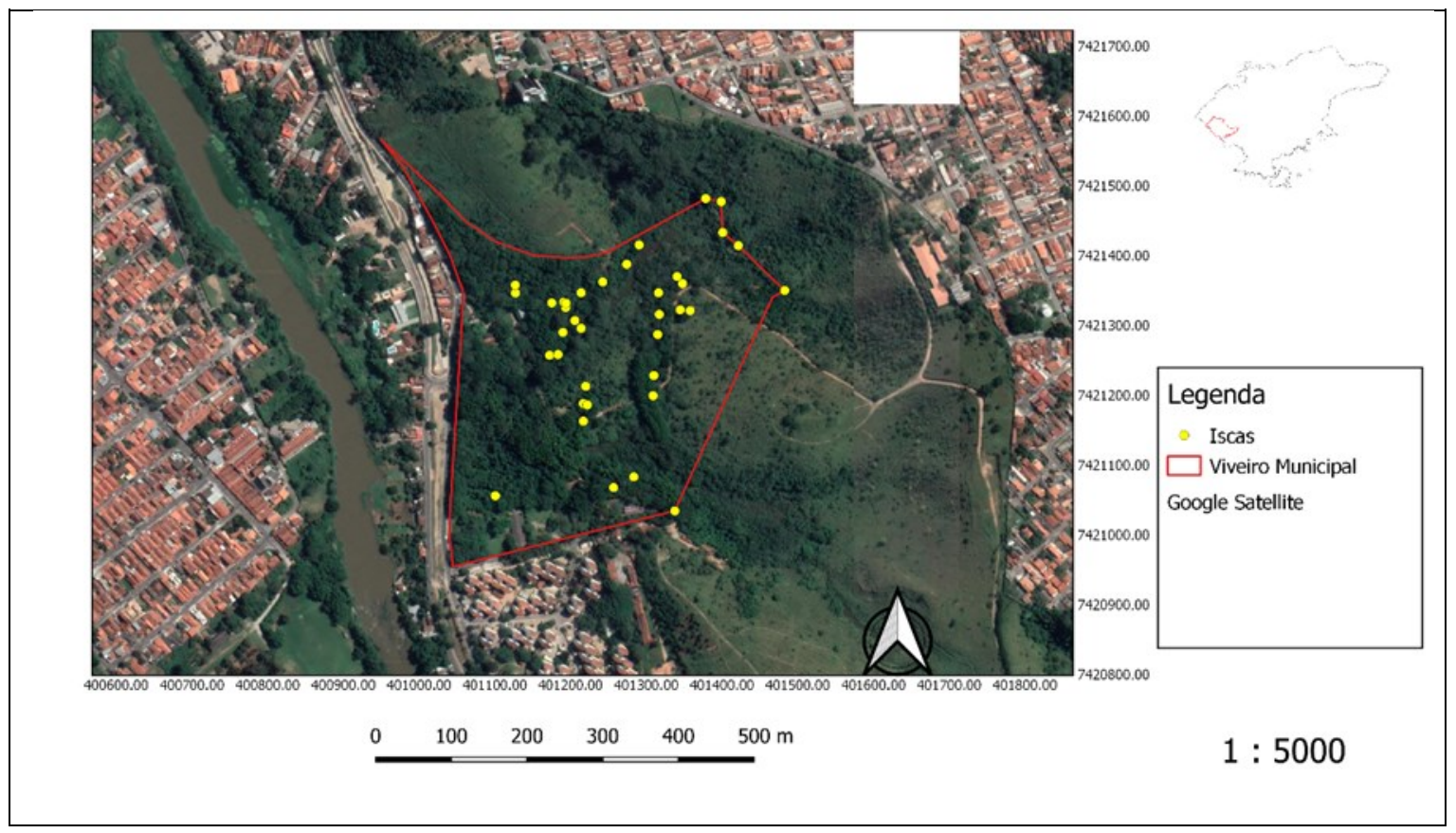

Figura 2. Viveiro Seo Moura e iscas georreferenciadas.

Na Etapa 2, foi definido e elaborado o banco de dados da área ampliada do estudo, que compreendeu o Vale do Paraíba, conforme Tabela 1.

Tabela 1. Camadas do banco de dados do estudo.

\begin{tabular}{ccc}
\hline Camada & Escala & Fonte \\
\hline Hidrografia & $1: 250.000$ & IBGE, 2020 \\
Limites municipais & $1: 250.000$ & IBGE, 2020 \\
K $_{\text {dLF }}\left(\mathrm{mol} \mathrm{L}^{-1}\right)$ & $1: 250.000$ & IBGE, 2020 \\
Limites estaduais & $1: 250.000$ & IBGE, 2020 \\
Uso e cobertura da terra & $1: 100000$ & SMA, 2010 \\
Malha viária & $1: 250.000$ & MI, 2020 \\
Unidades de conservação & $1: 100.000$ & MMA, 2020 \\
\hline
\end{tabular}

A região do Vale do Paraíba Paulista envolve 39 municípios e uma área de cerca de 16.180 $\mathrm{km}^{2}$. Dentro desta área de interesse foram realizados os recortes das camadas: unidades de conservações, uso e cobertura da terra, malha viária e hidrografia, conforme Figura 3. 

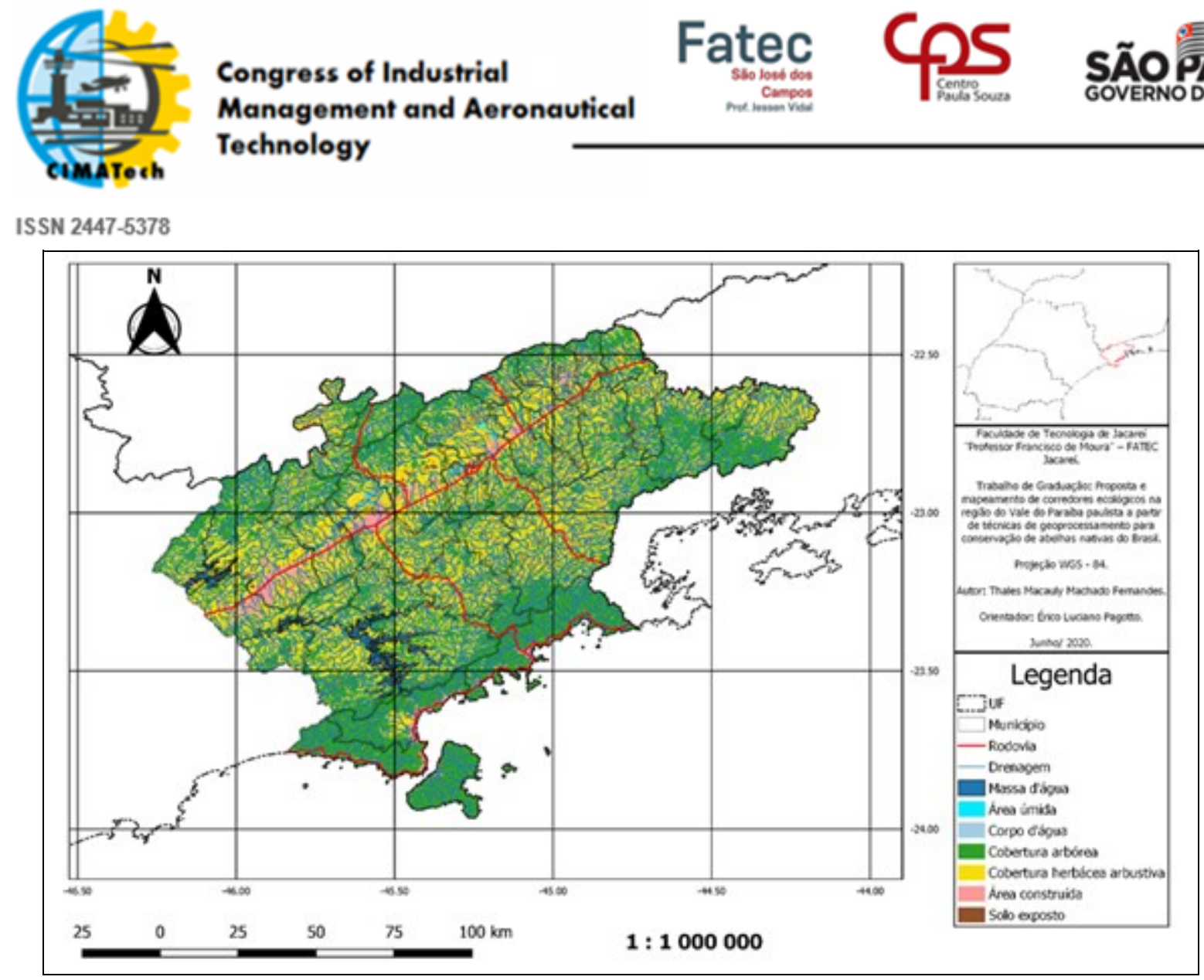

Figura 3. Croqui da área de interesse do estudo.

Para realizar os recortes, inicialmente foi necessário eliminar os erros que apresentavam nas geometrias obtidas, conhecido como erros topológicos, normalmente ocorrido por intersecção das geometrias. Então foi utilizado o verificador de topologia que é um complemento do QGIS. Topologia descreve as relações entre pontos, linhas e polígonos que representam as feições de uma região geográfica (QGIS, 2020).

Em seguida foi realizado o recorte das geometrias na área de interesse do estudo do Vale do Paraíba Paulista. O resultado dos recortes, referente ao banco de dados do estudo, contém:

- Unidades de conservações: áreas de proteção ambiental; estações ecológicas; floresta nacional; monumentos naturais; parques estaduais, nacionais e naturais municipais; reservas particulares de patrimônios naturais com seus respectivos centroides (Figura 4).

- Uso e cobertura da terra: área construída; área úmida; cobertura arbórea; cobertura herbácea arbustiva; corpo d'agua; solo exposto, sombra e nuvem.

- Hidrografia: trechos de drenagens e de massas d'água (Figura 5).

A partir desta cartografia básica, os dados foram tratados no ambiente SIG. Foram criados buffers no sistema de drenagem de $30 \mathrm{~m}$ e sobre o trecho de massa d'água de $250 \mathrm{~m}$, referente às áreas de preservação permanente destas feições, conforme determina o Código Florestal brasileiro (BRASIL, 2012). Dos mapas de uso e cobertura foram retiradas as feições que não fossem de cobertura arbórea, bem como as manchas de vegetação menores que 1.000 ha de forma a se obter os maciços vegetais com maior relevância ecológica (Figura 6).

Finalmente, na Etapa 3 foi elaborado o mapa final contendo a proposta dos corredores ecológicos. $\mathrm{O}$ modelo de geoprocessamento utilizado considerou a vegetação de porte arbóreo, as áreas de preservação permanente e as unidades de conservação como elementos favorecedores à criação de cada corredor, dado serem potenciais nichos ecológicos, e as áreas urbanizadas e estradas como elementos desfavorecedores (Figura 7). Também foi levado em consideração que a criação dos 
ISSN $2447-5378$

corredores deveria proporcionar a integração entre os fragmentos florestais da Serra do Mar e da Serra da Mantiqueira de forma a favorecer o fluxo gênico entre as duas fitofisionomias (Figura 8).

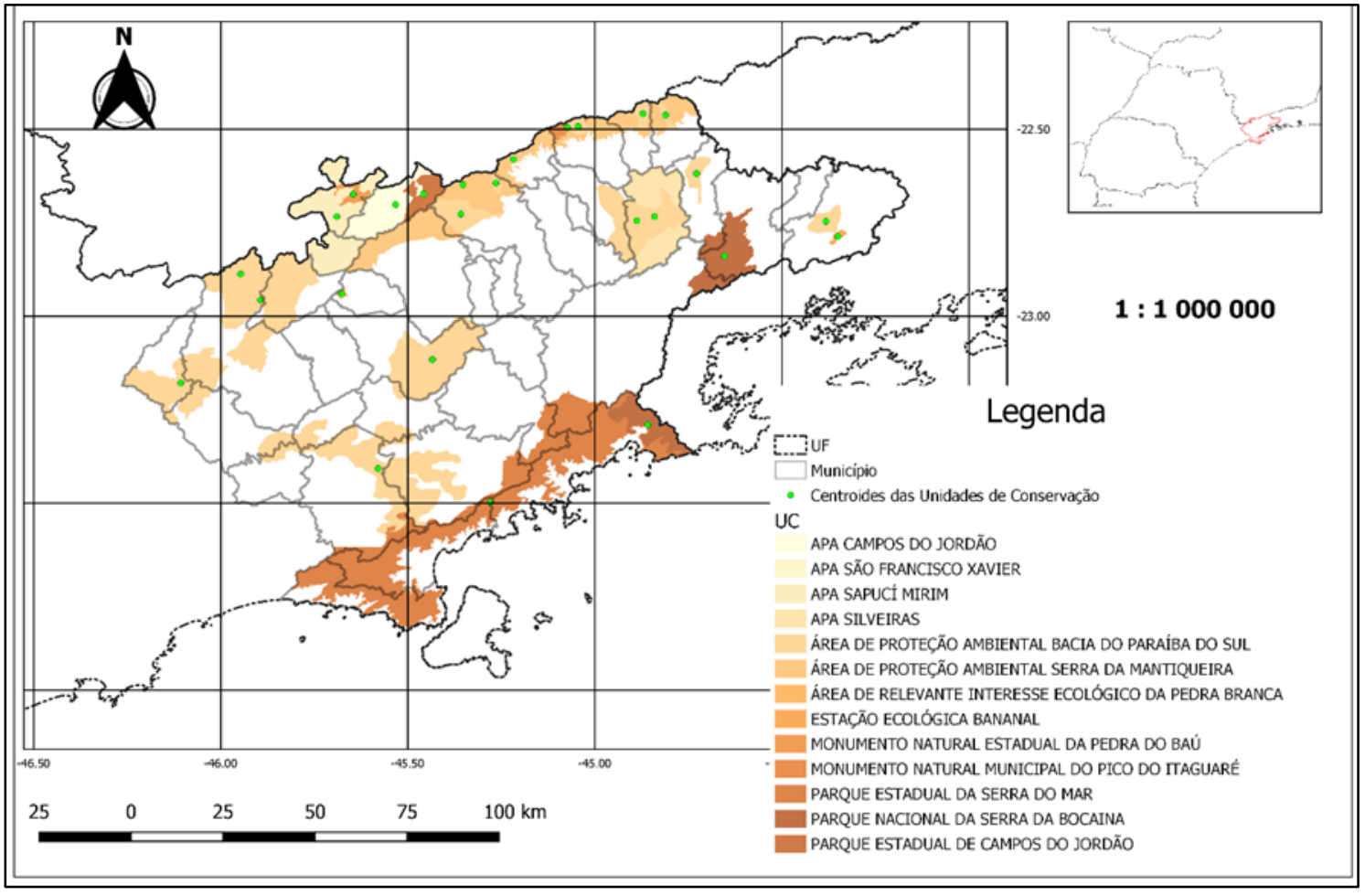

Figura 4. Unidades de conservação selecionadas e respectivos centroides.

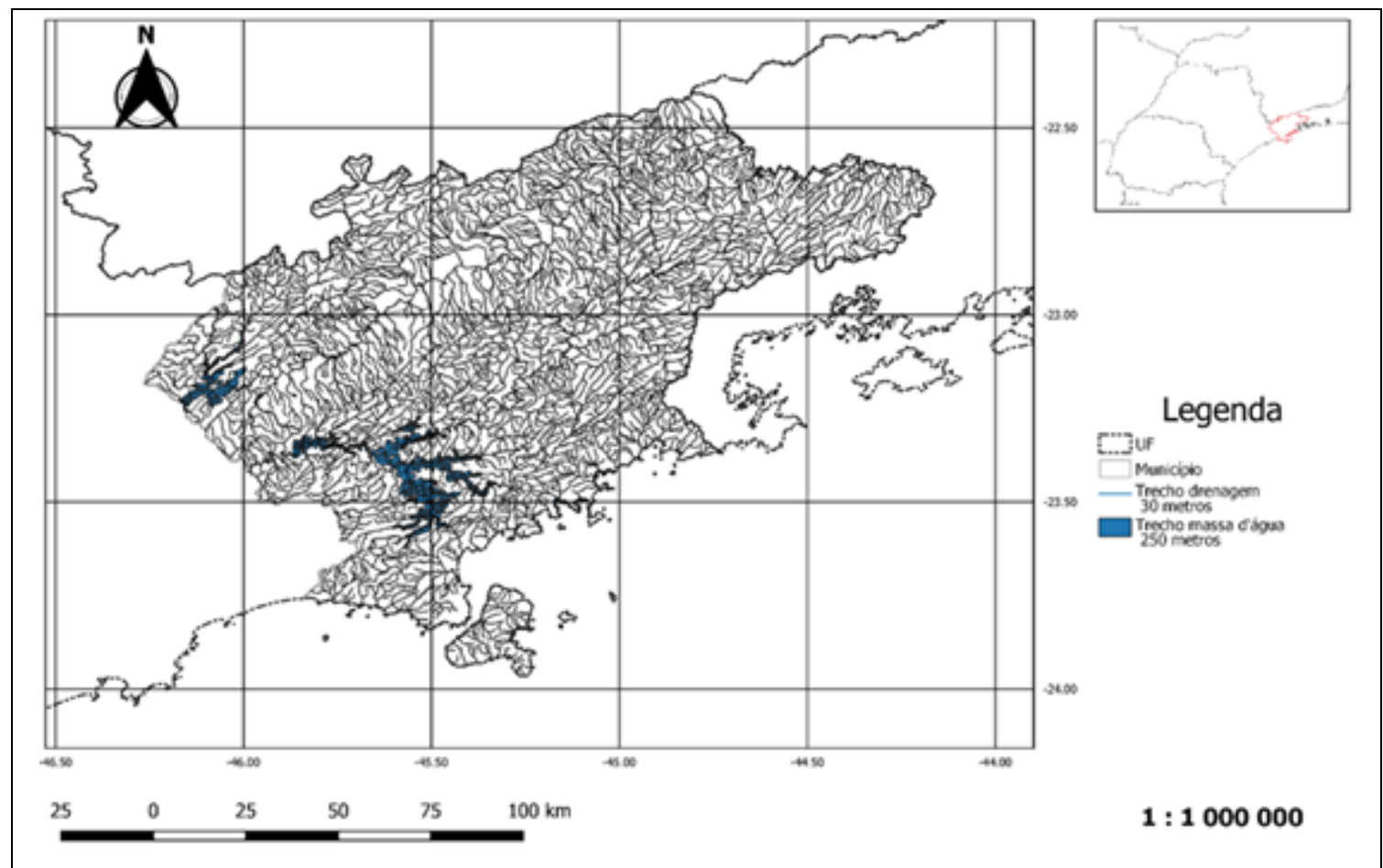

Figura 5. Rede de drenagem. 


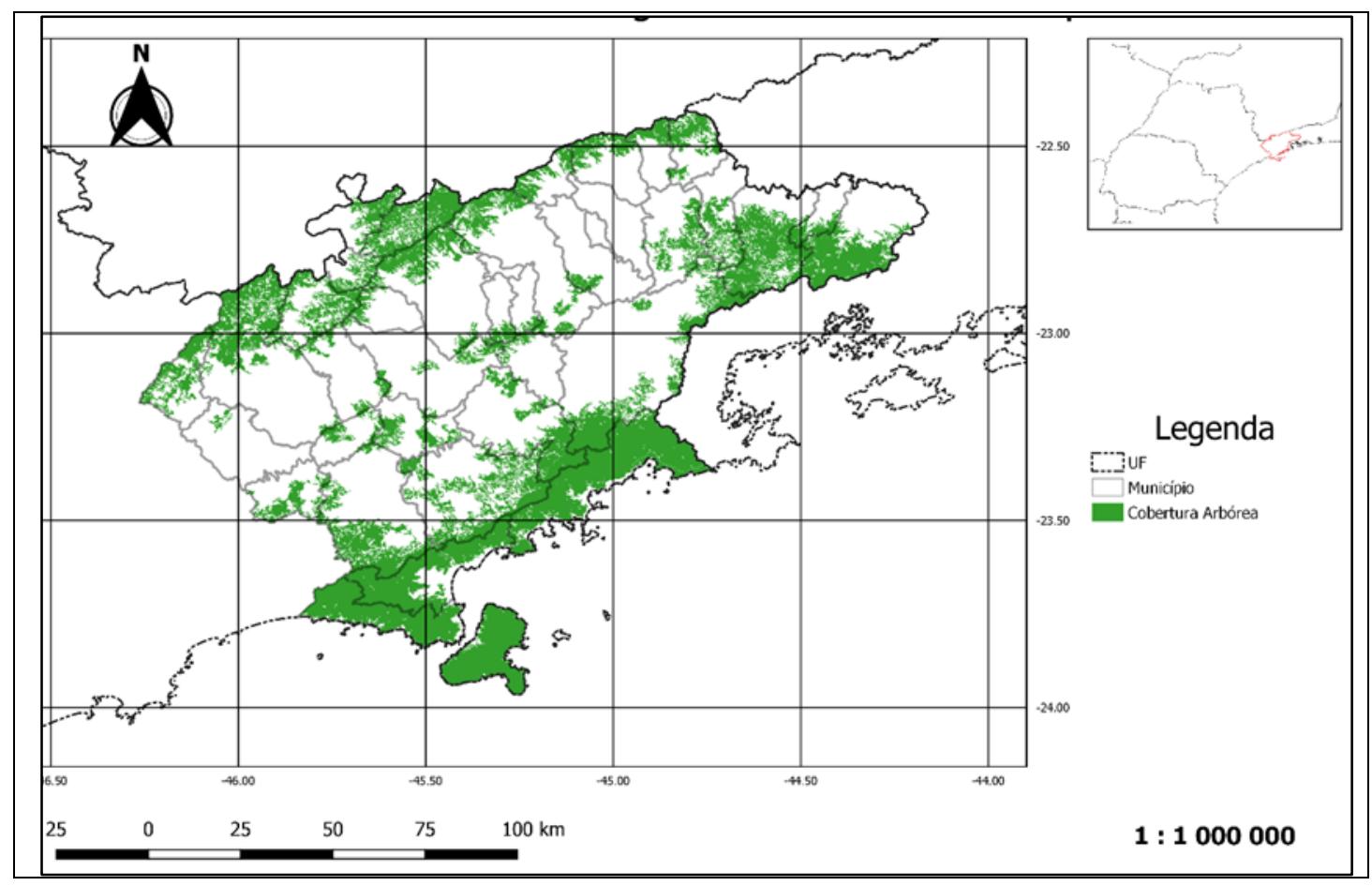

Figura 6. Cobertura arbórea superior a 1.000 ha.

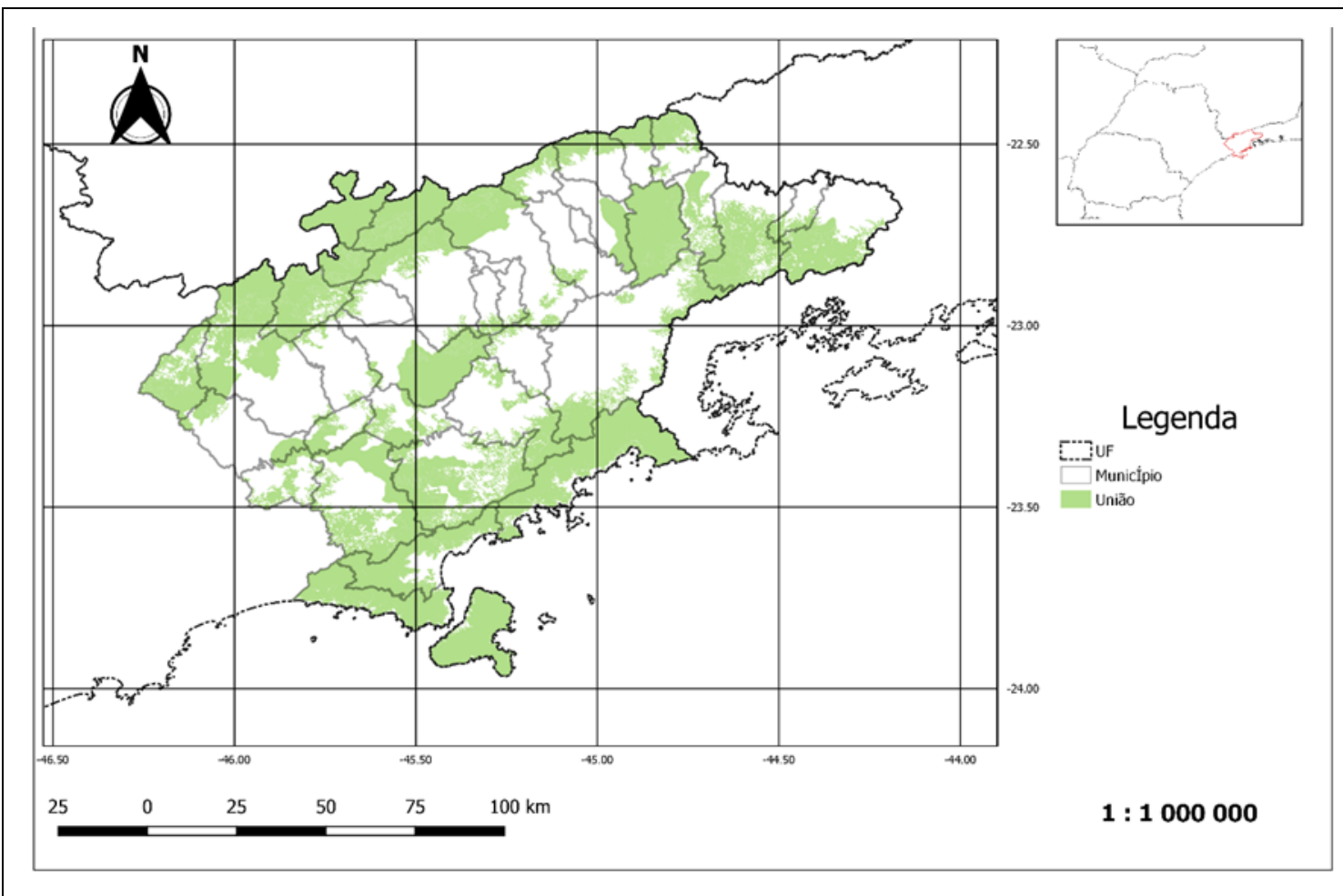

Figura 7. União entre as unidades de conservação e cobertura arbórea. 

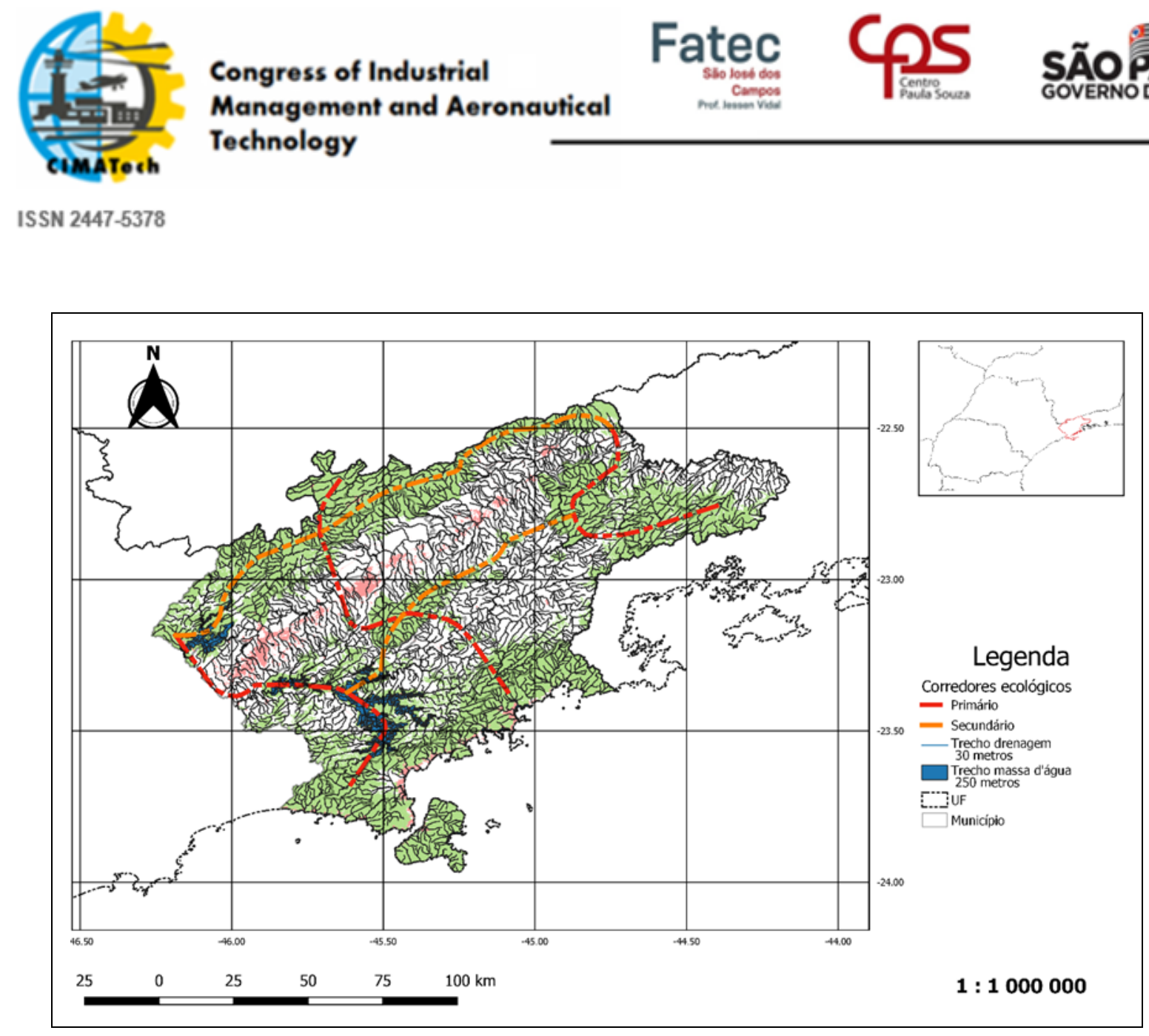

Figura 8. Proposta e mapeamento dos corredores ecológicos.

\section{RESULTADOS E DISCUSSÃO}

A primeira etapa do projeto consistiu na realização de um projeto-piloto no Viveiro de Jacareí para verificar a viabilidade de criação de um meliponário municipal a partir da técnica de captura com o uso de iscas espacialmente distribuídas em um fragmento florestal. Das 80 iscas, 4 resultaram em enxames e constituíram o início do meliponário municipal, demonstrando que é possível criar um meliponário com estas técnicas, inclusive em área pública, como foi o caso, a partir da mobilização de gestores locais.

A segunda e terceira etapas demonstraram que a existência de unidades de conservação no Vale do Paraíba, e seu arranjo espacial, assim como o das áreas de preservação permanente e maciços de vegetação, formam um mosaico desconexo que pode ser reconectado priorizando-se determinadas áreas para a restauração florestal na área dos corredores ecológicos.

O mapa final dos corredores ecológicos, interseccionado com os limites dos municípios, permite estabelecer quais são as áreas prioritárias em cada um - tanto para a criação de meliponídeos, que são aquelas de ocorrência de vegetação arbórea, como também as áreas prioritárias para restauração florestal. Dos 39 municípios que compõem a área de estudo 33 precisariam de algum nível de restauração florestal para reconectar os corredores ecológicos. A Tabela 2 apresenta uma relação daqueles com as maiores áreas a serem restauradas e que deveriam ser priorizados. 
Tabela 2. Municípios prioritários para restauração florestal por área.

\begin{tabular}{lc}
\hline \multicolumn{1}{c}{ Município } & Área (ha) \\
\hline Jacareí & $13.290,9$ \\
São Luís do Paraitinga & $10.450,0$ \\
Taubaté & $9.419,8$ \\
Lorena & $6.793,1$ \\
Guaratinguetá & $6.666,5$ \\
Cunha & $4.302,6$ \\
Queluz & $4.278,8$ \\
Redenção da Serra & $4.027,5$ \\
Caçapava & $2.948,6$ \\
Areias & $2.912,4$ \\
\hline
\end{tabular}

Também foi possível observar que a distribuição espacial das melhores áreas para criação dos corredores ecológicos permite a interligação da Serra da Mantiqueira com a Serra do Mar. Isto ampliaria significativamente a área de forrageamento das abelhas nativas (assim como de outros animais), favorecendo a conservação da diversidade biológica. Foram então estabelecidos os corredores que serão prioritários, que são aqueles que conectam a Serra do Mar à Serra da Mantiqueira, e os secundários, que são aqueles que conectam as unidades de conservação no sentido sudoeste à nordeste (Figura 8).

O mapeamento demonstrou que as maiores unidades de conservação estão desconectadas entre si, o que poderia ser revertido por meio de incentivos do poder público local à restauração florestal com vistas à criação de corredores ecológicos, trazendo benefícios ao fluxo gênico entre as abelhas e demais espécies animais e vegetais. Como no trabalho desenvolvido por Moretti (2011), foi possível utilizar técnicas de geoprocessamento para identificar locais adequados para alocação dos corredores ecológicos - aqui, voltado à conservação das abelhas. $\mathrm{O}$ mapeamento realizado é uma ferramenta essencial tanto na proposta dos corredores ecológicos, como para priorização das áreas a serem preservadas, dos quais as abelhas são bioindicadores.

\section{CONCLUSÃO}

O objetivo deste trabalho foi elaborar uma proposta de corredores ecológicos para conservação de meliponídeos no Vale do Paraíba. Esta pesquisa demonstrou que o estudo de caso realizado no Município de Jacareí foi bem sucedido e pode ser reproduzido em outras localidades. A etapa de mapeamento permitiu definir as áreas mais favoráveis à criação dos corredores ecológicos, bem como quais poderiam ser priorizadas em cada município para a instalação de meliponários como o de Jacareí.

Para que isso seja de fato implementado, é importante que cada município operacionalize políticas públicas locais e recursos - seja para a criação de meliponários municipais, seja para incentivar produtores rurais a investirem em meliponicultura. 


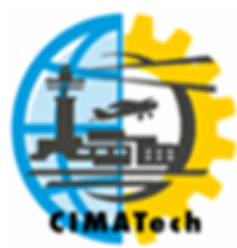

As abelhas desempenham um papel fundamental nos ecossistemas ao atuarem como polinizadores. As abelhas nativas, em particular, devem ser priorizadas, uma vez que se encontram em extinção por conta do avanço do desmatamento e do uso de agrotóxicos. Por outro lado, a meliponicultura também é uma atividade econômica geradora de emprego e renda.

A criação dos corredores ecológicos permite ainda conectar as unidades de conservação entre si, e estas com fragmentos isolados, de forma que todo habitat será beneficiado com a criação dos corredores. Regiões com vegetação isolada podem ser restauradas e assim conectar demais áreas, preservando a natureza e seus elementos. Então é interessante que novos meliponários sejam criados pelos demais municípios da região do Vale do Paraíba e atualização das bases disponíveis pelos órgãos públicos e monitoramento contínuo dos meliponários.

Os corredores ecológicos são importantes dos pontos de vistas social, econômico, gerando fonte de emprego e renda as pessoas, e ambiental devido a proteger as abelhas que sustentam boa parte da cadeia trófica.

Quanto às limitações desta pesquisa, a primeira delas foi que o projeto-piloto foi realizado apenas no Município de Jacareí, e outros municípios podem estar sob condições diferentes. Outra limitação foi a utilização apenas de dados secundários. Neste caso, é importante haver atualização, principalmente do uso do solo, validando o traçado dos corredores propostos. Então recomenda-se que os demais municípios se mobilizem para criação dos seus meliponários, principalmente nas regiões onde foram propostos os corredores, e que projetos de conservação ambiental sejam desenvolvidos pelos municípios do Vale do Paraíba, onde observa-se uma grande fragmentação de habitats, ou seja, as grandes massas de vegetação estão ficando cada vez mais isoladas entre si, então é interessante começar a pensar na reconexão desses fragmentos.

\section{AGRADECIMENTOS}

Agradecemos à FATEC Jacareí, ao Instituto Abepoli e ao Viveiro Municipal de Jacareí pelo apoio a este projeto ao longo de todas suas etapas.

\section{REFERÊNCIAS}

ALVES, T. T. L; MENESES, A. R. V DE; SILVA, J. N; PARENTE, G. D. L; NETO, J. P. DE H. Caracterização físico-química e avaliação microbiológica de méis de abelhas nativas do nordeste brasileiro. Revista Verde (Mossoró - RN - Brasil) v.6, n.3, p.91 - 97, julho/ setembro de 2011.

BRASIL. Lei no 12.651, de 25 de maio de 2012. Dispõe sobre a proteção da vegetação nativa; altera as Leis no 6.938, de 31 de agosto de 1981, 9.393, de 19 de dezembro de 1996, e 11.428, de 22 de dezembro de 2006; revoga as Leis no 4.771, de 15 de setembro de 1965, e 7.754, de 14 de abril de 1989, e a Medida Provisória no 2.166-67, de 24 de agosto de 2001; e dá outras providências. Disponível em: http://www.planalto.gov.br/ccivil_03/_ato20112014/2012/lei/L12651 compilado.htm. Acesso em: 01/out/2020.

BURROUGH, P.A. Principles of geographical information systems for land resources assessment. Oxford: Clarendon, 1986. 


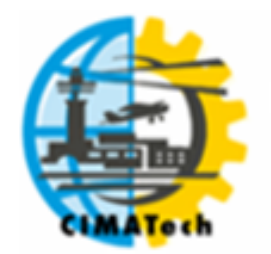

ISSN $2447-5378$

CAMARGO. R.C.R. A Criação de Abelhas Nativas como Opção na Geração e Renda para a Comunidade Local na Reserva Extrativista do Delta do Parnaíba. Embrapa Meio-Norte, 2004.

COWEN, D. J. GIS versus CAD versus DBMS: what are the differences? Photogrammetric Engineering and Remote Densing, v. 54, p. 1551-1554, 1988.

DUTRA R. P. et al. Avaliação farmacognóstica de geoprópolis de Melipona fasciculata Smith da Baixada maranhense, Brasil. Rev. Bras. Farmacognosia, v.18, n.4, p. 557-562, out./dez. 2008.

GUIMARÃES, T.; PAGOTTO, E. Guia prático com técnicas de manejo de abelhas nativas sem ferrão. Monografia de conclusão de curso. Fatec Prof. Francisco de Moura, Jacareí, 2020.

INSTITUTO NACIONAL DE PESQUISAS ESPACIAIS. Disponivel em $<$ http://www.dpi.inpe.br/spring/portugues/tutorial/introducao_geo.html>. Acesso em 29 fev 2020.

IBGE - Instituto Brasileiro de Geografia e Estatística. GeoFTP. Disponível em: $<\mathrm{ftp}$ ://geoftp.ibge.gov.br/>. Acesso em 19 mai 2020.

MMA - Ministério do Meio Ambiente. Dados Georreferenciados. Cadastro Nacional UC'S. Disponível em: $<$ https://www.mma.gov.br/areas-protegidas/cadastro-nacional-de-ucs/dadosgeorreferenciados.html>. Acesso em 18 mai 2020.

MEDEIROS, J. S. DE; CÂMARA, G. Geoprocessamento para projetos ambientais. INPE - São José dos Campos, 2001.

MI - Ministério da Infraestrutura. Mapas e Bases dos Modos de Transportes. Disponível em: $<$ http://www.infraestrutura.gov.br/component/content/article/63-bit/5124-bitpublic.html\#maprodo>. Acesso em 18 mai 2020.

MORETTI, A. I. P. Mapeamento de corredores ecológicos na APA Fernão Dias - MG a partir de técnicas de geoprocessamento e análise espacial. Universidade Estadual de Campinas Instituto de Geociências. Dissertação de Mestrado: 149/2011.

SENA, F. T. N. DE S; NETO, B. V. J. S; LEITE, A. C. DE S. Uso do geoprocessamento como subsídio à análise Ambiental: Imagem SRMT na geração dos mapas hipsòmétrico e de declividadee das bacias difusas da barrage boa esperança no estado do Piauí. IV Simpósio Brasileiro de Ciências Geodésicas e Tecnologias da Geoinformação, p. 001 - 005, 2012.

SMA - Secretaria de Meio Ambiente do Estado de São Paulo. Mapa de Cobertura da Terra do Estado de São Paulo. Disponivel em: $<$ https://www.infraestruturameioambiente.sp.gov.br/cpla/mapa-de-cobertura-da-terra-do-estado-desao-paulo/>. Acesso em 23 mai 2020.

VENTURIERI, G. C. Capacitação em Meliponicultura no Estado do Pará. Congresso, Seminários e Encontros Brasileiros de Apicultura. Anais. 4 ${ }^{\mathrm{a}}$. Ed. 2006. Disponível em: < https://www.alice.cnptia.embrapa.br/bitstream/doc/580128/1/ID42117.pdf >. Acesso em: 19 mai. 2020. 
VERONEZ, M. R. Proposta de parâmetros de transformações entre sistemas WGS-84 e o SAD69 para região de São Carlos. Dissertação de mestrado. Escola de Engenharia de São Carlos da Universidade de São Paulo. 1998. 113p. 